\title{
Enhancing packaging board properties using micro- and nanofibers prepared from recycled board
}

\author{
Ossi Laitinen (1] · Terhi Suopajärvi • Henrikki Liimatainen
}

Received: 13 January 2020/ Accepted: 23 May 2020/Published online: 29 May 2020

(C) The Author(s) 2020

\begin{abstract}
In this study, cellulose microfibers and cellulose nanofibers (CNF) prepared from recycled boxboard pulp using a mechanical fine friction grinder were used as reinforcements in a board sheet. Microand nanofibers manufactured by mechanical grinding have typically broad particle size distribution, and they can contain both micro- and nano-sized fibrils. Deep eutectic solvent of choline chloride and urea was used as a non-hydrolytic pretreatment medium for the $\mathrm{CNF}$, and reference CNF were used without any chemical pretreatment. The CNF were ground using three grinding levels (grinding time) and their dosage in the board varied from 2 to $6 \mathrm{wt} \%$. The results indicate that the board properties could be tailored to obtain a balance between the processability and quality of the products by adjusting the amount of CNF that was added (2-6 wt \%). A preliminary cost assessment indicated that the most economical way to
\end{abstract}

Electronic supplementary material The online version of this article (https://doi.org/10.1007/s10570-020-03264-w) contains supplementary material, which is available to authorized users.

O. Laitinen $(\bowtie) \cdot$ T. Suopajärvi · H. Liimatainen

Fiber and Particle Engineering, University of Oulu, P.O. Box 4300, 90014 Oulu, Finland

e-mail: ossi.laitinen@oulu.fi

T. Suopajärvi

e-mail: terhi.suopajarvi@oulu.fi

H. Liimatainen

e-mail: henrikki.liimatainen@oulu.fi enhance the board strength properties was to add around $4 \%$ of CNF with a moderate grinding level (i.e., grinding energy of $3-4 \mathrm{kWh} / \mathrm{kg}$ ). Overall, the strength properties of the manufactured board sheets improved by several dozen percentages when CNF was used as the reinforcement.

Keywords Boxboard · Cellulose nanofibers · Deep eutectic solvents · Fine friction grinding · Microfibers . Nanocellulose $\cdot$ Reinforcement

\section{Introduction}

The production of nano-scale cellulose fibers (nanocelluloses) and their application as reinforcements in materials have gained increasing attention due to the high strength and stiffness of the nanocelluloses combined with their small size, high surface area and aspect ratio, low weight, biodegradability, and renewability (Siró and Plackett 2010; Hassan et al. 2011; Suopajärvi et al. 2017). Cellulose nanofibrils or nanofibers (CNF) produced by mechanical disintegration of cellulose without any chemical treatments are one of the simplest types of nanomaterials based on renewable resources. CNF manufactured by mechanical treatments alone are polydisperse with a broad particle size distribution, and they can contain both micro- and nano-sized fibrils (Kangas et al. 2014). 
CNF have both amorphous and crystalline components, and they form of a web-like structure (Lavoine et al. 2012).

The mechanical fibrillation process causes permanent changes in the cellulose fiber structure, and it increases the bonding ability of cellulose by modifying the morphology and reducing the size of the fibers (Kamel 2007; da Costa Correia et al. 2016). Thus, some previous studies have shown that CNF can notably improve the mechanical properties of paper or board. It has been found that tensile strength and elastic modulus can be improved significantly (Eriksen et al. 2008; Hii et al. 2012; Sehaqui et al. 2013; González et al. 2013; Missoum et al. 2013; Djafari Petroudy et al. 2014; Hietala et al. 2016). High tensile strength and tensile stiffness contribute to the stacking strength of corrugated paperboard by reducing the risk of box wall bulging; thus, they are desired properties of board applications.

The global increase in packaging board and fiber products consumption has yielded a large amount of potential secondary cellulose raw materials that contribute to $25-40 \%$ of municipal solid waste (Nourbakhsh and Ashori 2010). Recycling these fiber sources and their use as raw materials for new sustainable products can preserve forest resources and minimize other environmental impacts. Moreover, fibers from recycled paper and packaging are relatively affordable and widely available. Therefore, they offer an appealing source for the production of packaging materials and novel green materials, such as CNF. The use of bio-based and recycled fiber sources to create sustainable packaging materials to replace plastics derived from fossil oil resources promotes the emerging trend of mitigating the carbon footprint of materials.

The successful liberation of nanofibrils require typically rigorous mechanical treatments due to the strong hydrogen-bonded structure of cellulosic materials. Thus, numerous different chemical pretreatments have been used to loosen the rigid structure of cellulose. Deep eutectic solvents (DESs) belong to the most promising group of novel green chemicals to enable efficient CNF production (Selkälä et al. 2016; Li et al. 2017, 2018; Sirviö 2018; Ojala et al. 2018). DESs can be derived from biodegradable and readily available green compounds that have a low toxicity (Sirviö et al. 2015). DESs are typically synthesized by complexation of the hydrogen bond acceptor (HBA), such as a halide salt of quaternary ammonium or a phosphonium cation along with a hydrogen bond donor (HBD) (e.g., urea, glycerol, or ethylene glycol), to form a mixture that exhibits a notably lower melting point than either HBA or HBD. In the present work, a DES system based on choline chloride and urea (Singh et al. 2012) was used as a pretreatment to liberate CNF from recycled boxboard using mechanical grinding. The CNF obtained from a secondary cellulose source were further used as reinforcements in board sheets. CNF produced directly from recycled board without any chemical treatments were used as the reference additives. Nanopapers were produced from the CNF to evaluate their strength properties. Moreover, the work evaluated the optimal grinding level in CNF production to maximize the energy consumption and costs of manufacturing CNF for use as board reinforcements.

\section{Materials and methods}

Raw material and chemicals

\section{Chemicals used}

Urea (97\%) and choline chloride (>98\%) for DES were purchased from Borealis (Austria) and Algry Quimica (Spain), respectively. All chemicals were used as delivered, without any further purification. In the dilutions and CNF production, deionized water was used throughout the experiments.

\section{Raw material}

Recycled boxboard was obtained directly from boardcontainer collections, and it was used as the raw material for the board sheets and the production of the CNF. The boxboard was first pulped without any additional chemicals using a Kenwood Chef Titanium XL pulper (UK) with a nominal rotor power of $1700 \mathrm{~W}$, which has an operating principle similar to that of the Hobart pulper, at a consistency of $15 \%$ using a temperature of $45{ }^{\circ} \mathrm{C}$. Pulper using a planetary type mixing during pulping procedure. The mixer and pulping bowl were manufactured in stainless steel. Pulping time was adjusted to $10 \mathrm{~min}$ and rotor speed 2 (i.e., $250 \mathrm{rpm}$ ). After pulping, the recycled boxboard pulp was washed and screened using a Somerville screen (Lorentzen and Wettre, Sweden). 
The conductometric titration procedure described by Rattaz et al. (2011) and Katz et al. (1984) was used to determine the charge density of the pulp. The hemicellulose content was determined with the TAPPI-T 212 om-02 standard and alkali solubility at $25{ }^{\circ} \mathrm{C}$ was determined with the TAPPI-T $235 \mathrm{~cm}-00$ standard. The lignin content was determined using TAPPI-T 222 om-02 standard. Moreover, the extractive content was analyzed using SCAN-CM 49:03 standard and ash content was determined using the ISO1762 standard. The chemical properties of the board raw material are shown in Table 1 . The average (length-weighted) length and width of the board fibers after washing were determined with a Valmet FS5 Fiber analyzer ultra-high definition (UHD) camera unit (Finland). Three replicates of each sample were measured, and the results were averaged and shown in Table 2.

\section{Production of CNF from the recycled boxboard}

DES of choline chloride and urea was used as a pretreatment to produce CNF from the boxboard pulp. The DES solution was produced by heating $1620 \mathrm{~g}$ of choline chloride and $1223 \mathrm{~g}$ of urea in a large beaker $\left(5 \mathrm{dm}^{3}\right)$ at $100{ }^{\circ} \mathrm{C}$ until the mixture melted, after which it was placed into a water bath at $100{ }^{\circ} \mathrm{C}$ under constant stirring for approximately $5 \mathrm{~min}$ to obtain a clear and colorless liquid. Then, $25 \mathrm{~g}$ (abs) of recycled board material (dry matter content of $\sim 30 \%$ ) was added to the suspension and mixed for $2 \mathrm{~h}$. Then, the beaker was removed from the water bath and $1000 \mathrm{~cm}^{3}$ of deionized water was added while mixing (Sirviö et al. 2015). Next, four identical DES-treated batches of boxboard pulp were combined. Then, the treated board was washed with water using a Somerville screen (Lorentzen and Wettre) until clear rinse water was obtained.

After completing the washing procedure, the DEStreated pulp was disintegrated with a Masuko supermasscolloider grinder (MKCA6-2J, Japan) using three different grinding times (grinding energy) to obtain three different CNF samples: T1, T2, and T3 (Table 3). The stones of the grinder were first carefully brought into close contact, as determined by the low friction sound, and then the pretreated pulp slurry was poured into the grinder at a consistency of $1.5 \%$. First, the pulp was passed through the grinder three times using a zero-grinding stone gap (sample: T0); after which the stones were adjusted to negative gap values in order to start the actual fibrillation. The energy consumption of the fibrillation procedure was recorded with an energy meter (iEM3250 SchneiderElectric, France) attached to the fine friction grinder. The board pulp passed through the grinder a total of 14 times, using negative gap values of 3 times $-20 \mu \mathrm{m}$, 1 time $-40 \mu \mathrm{m}, 1$ time $-50 \mu \mathrm{m}, 1$ time $-60 \mu \mathrm{m}, 3$ times $-80 \mu \mathrm{m}$, and 5 times $-90 \mu \mathrm{m}$ to obtain different board CNF (Table 3). The reference CNF samples were obtained from untreated boxboard pulp using a similar procedure. The reference samples are named: U0, U1, U2 and U3.

Manufacture and characterization

of the investigated materials

\section{Visualization of CNF and the board samples}

After being subjected to different grinding energies, the board pulps were visualized using a Valmet FS5 Fiber analyzer UHD camera unit. Field emission scanning electron microscope (FESEM) (Zeiss Ultra Plus, Germany) was used for the samples obtained after a longer grinding time because of their much smaller average particle size and the need for a higher magnification. As a pretreatment, the FESEM samples were filtered using a polycarbonate membrane with a pore size of $0.2 \mu \mathrm{m}$ (Whatman). Then, the filtration samples were rapidly frozen with liquid nitrogen and freeze-dried in a vacuum overnight. The dried samples were sputter-coated with platinum. An accelerating voltage of $5 \mathrm{kV}$ and a working distance of around $5 \mathrm{~mm}$ was used when imaging the samples.

Table 1 Chemical properties of the recycled boxboard pulp

\begin{tabular}{lllllll}
\hline Sample & Charge $(\mathrm{mmol} / \mathrm{g})$ & Cellulose $(\mathrm{wt} \%)$ & Hemicel-lulose $(\mathrm{wt} \%)$ & Lignin $(\mathrm{wt} \%)$ & Extrac-tives (wt\%) & Ash (wt $)$ \\
\hline Board & -0.19 & 57.5 & 16.4 & 13.3 & 0.8 & 12.3 \\
\hline
\end{tabular}


Table 2 Fiber properties of the recycled board pulp ground with a fine friction grinder including standard deviation of measurements

\begin{tabular}{|c|c|c|c|c|c|c|c|}
\hline Sample & $\begin{array}{l}\text { Fiber length } \\
(\mathrm{mm})\end{array}$ & $\begin{array}{l}\text { Fiber width } \\
(\mu \mathrm{m})\end{array}$ & $\begin{array}{l}\text { Fines A1, } \\
0-0.04 \mathrm{~mm} \\
(\%)\end{array}$ & $\begin{array}{l}\text { Fines A2, } \\
0.04-0.08 \mathrm{~mm} \\
(\%)\end{array}$ & $\begin{array}{l}\text { Fines A3, } \\
0.08-0.12 \mathrm{~mm} \\
(\%)\end{array}$ & $\begin{array}{l}\text { Fines A4, } \\
0.12-0.16 \mathrm{~mm} \\
(\%)\end{array}$ & $\begin{array}{l}\text { Fines A5, } \\
0.16-0.20 \mathrm{~mm} \\
(\%)\end{array}$ \\
\hline T0 & $0.763 \pm 0.018$ & $19.27 \pm 0.70$ & $1.94 \pm 0.24$ & $1.25 \pm 0.07$ & $0.85 \pm 0.04$ & $0.68 \pm 0.04$ & $0.65 \pm 0.03$ \\
\hline $\mathrm{T} 1$ & $0.148 \pm 0.001$ & $6.42 \pm 0.04$ & $20.72 \pm 0.09$ & $11.39 \pm 0.04$ & $5.7 \pm 0.02$ & $3.69 \pm 0.03$ & $2.72 \pm 0.02$ \\
\hline $\mathrm{T} 2$ & $0.053 \pm 0.002$ & $3.60 \pm 0.10$ & $44.63 \pm 1.19$ & $22.93 \pm 0.27$ & $9.47 \pm 0.32$ & $4.91 \pm 0.18$ & $2.87 \pm 0.14$ \\
\hline $\mathrm{T} 3$ & $0.042 \pm 0.002$ & $2.14 \pm 0.09$ & $64.77 \pm 2.25$ & $24.41 \pm 0.94$ & $7.06 \pm 0.77$ & $2.18 \pm 0.35$ & $0.69 \pm 0.15$ \\
\hline U0 & $0.787 \pm 0.033$ & $19.53 \pm 0.84$ & $1.42 \pm 0.16$ & $1.02 \pm 0.04$ & $0.74 \pm 0.03$ & $0.69 \pm 0.02$ & $0.64 \pm 0.01$ \\
\hline U1 & $0.138 \pm 0.003$ & $6.66 \pm 0.09$ & $22.96 \pm 0.21$ & $11.87 \pm 0.09$ & $6.45 \pm 0.08$ & $4.35 \pm 0.08$ & $3.11 \pm 0.07$ \\
\hline U2 & $0.057 \pm 0.001$ & $4.39 \pm 0.11$ & $38.96 \pm 0.87$ & $20.91 \pm 0.43$ & $10.01 \pm 0.26$ & $5.94 \pm 0.16$ & $4.00 \pm 0.01$ \\
\hline $\mathrm{U} 3$ & $0.037 \pm 0.001$ & $1.87 \pm 0.09$ & $72.51 \pm 1.89$ & $21.37 \pm 1.26$ & $4.58 \pm 0.46$ & $1.05 \pm 0.12$ & $0.26 \pm 0.03$ \\
\hline
\end{tabular}

Table 3 Energy consumption of the CNF production and the strength properties of the CNF nanopapers including standard deviation of measurements

\begin{tabular}{llllccc}
\hline Sample & Description & $\begin{array}{l}\text { Grinding time } \\
(\mathrm{min})\end{array}$ & $\begin{array}{l}\text { Energy consumption }(\mathrm{kWh} / \\
\mathrm{kg})\end{array}$ & $\begin{array}{l}\text { Density }(\mathrm{kg} / \\
\left.\mathrm{m}^{3}\right)\end{array}$ & $\begin{array}{l}\text { Tensile strength } \\
(\mathrm{MPa})\end{array}$ & Strain $(\%)$ \\
\hline T0 & Fibers & 0 & 0 & $568.4 \pm 8.0$ & $14.0 \pm 0.1$ & $1.32 \pm 0.01$ \\
T1 & CNF & 37 & 1.6 & $881.9 \pm 26.6$ & $66.0 \pm 3.4$ & $2.54 \pm 0.01$ \\
T2 & CNF & 67 & 3.7 & $1220.0 \pm 6.4$ & $156.1 \pm 12.6$ & $7.61 \pm 0.09$ \\
T3 & CNF & 114 & 8.8 & $1459.2 \pm 0.4$ & $181.8 \pm 24.1$ & $9.95 \pm 0.13$ \\
U0 & Fibers & 0 & 0 & $597.5 \pm 24.4$ & $16.7 \pm 0.4$ & $1.12 \pm 0.01$ \\
U1 & CNF & 30 & 1.0 & $832.1 \pm 42.0$ & $36.7 \pm 0.6$ & $1.89 \pm 0.01$ \\
U2 & CNF & 60 & 2.6 & $1109.9 \pm 67.3$ & $102.7 \pm 6.8$ & $5.46 \pm 0.02$ \\
U3 & CNF & 135 & 9.9 & $1418.1 \pm 23.0$ & $154.2 \pm 18.4$ & $9.35 \pm 0.16$ \\
\hline
\end{tabular}

The surface structure of different handsheets was visualized directly from the surface of the prepared handsheets, which were sputtered with platinum before observation under the FESEM with $5 \mathrm{kV}$ voltage.

\section{Testing the strength properties of the nanopapers produced from board treated with $\mathrm{CNF}$}

Nanopapers were produced by filtration of $0.3 \mathrm{~g}$ (abs) of the fibrillated board samples on a polyvinylidene fluoride membrane (Durapore) with a pore size of $0.65 \mu \mathrm{m}$ and a diameter of $70 \mathrm{~mm}$. After filtration, the wet sheets were covered with a similar membrane and then dried with a Rapid-Köthen sheet dryer (Karl Schröder KG, Germany) under a vacuum of 0.1 bar at a temperature of $93{ }^{\circ} \mathrm{C}$ for $10 \mathrm{~min}$ (ISO 5269-2:2004). The samples were stored at ISO 187 standard conditions of $23{ }^{\circ} \mathrm{C}$ and $50 \%$ relative humidity. After preconditioning for at least $48 \mathrm{~h}$ in the standard environment, five thicknesses of the sample in different locations were measured using a precision thickness gauge (Hanatek FT3, UK), and the results were averaged. Six strips with a width of $5 \mathrm{~mm}$ were used for the actual strength measurements. The tensile tests were performed with a Zwick D0724587 (Switzerland) universal material testing machine using a $100 \mathrm{~N}$ load cell (Table 3). During the tensile tests, six replicates of each sample were tested using the standard conditions of $23{ }^{\circ} \mathrm{C}$ temperature and $50 \%$ relative humidity. The gauge length was adjusted to $40 \mathrm{~mm}$ at a strain rate of $4 \mathrm{~mm} / \mathrm{min}$. 
Manufacturing and testing of the board handsheets

Laboratory handsheets were prepared from recycled boxboard pulp using various dosages $(0 \%, 2 \%, 4 \%$, or $6 \%$ ) of $\mathrm{CNF}$ as a reinforcement. $\mathrm{CNF}$ were added directly to the pulp board slurry without any other chemical additives. Board sheets with $160 \mathrm{~g} / \mathrm{m}^{2}$ grammage were prepared in a laboratory sheet-forming machine (Lorentzen and Wettre) according to the ISO 5269-1 standard method.

The board handsheets were conditioned before testing at $23{ }^{\circ} \mathrm{C}$ in $50 \%$ relative humidity according to the ISO 187 standard. Eight handsheets which means in practice at least eight replicates of each sample were tested using the standard conditions. The grammage and thickness of the handsheets were measured according to ISO 536 and ISO 534 standards. The tensile strength of the board handsheets was measured with a Zwick D0724587 universal material testing machine according to the ISO 1924-2 standard using $15 \mathrm{~mm} \times 141 \mathrm{~mm}$ test strips. The internal bond strength of the paperboard (z-direction tensile strength) was measured with a Zwick D0724587 machine according to the TAPPI T541, 09/2005 standard. The tearing strength was measured with the Lorentzen and Wettre Tearing Tester according to TAPPI T414 om-12.

\section{Results and discussion}

Characteristics of the board fibers and CNF

The visual appearance of the DES-treated board fibers and CNF obtained from grinding (Fig. S1) were studied with Valmet FS5 Fiber analyzer UHD camera unit (samples T0, T1, T2, and T3). Furthermore, example images (Fig. S2) of the DES-treated CNF (T2 and T3) were obtained with FESEM. Length weighted fiber length and width of each sample are presented in Table 2. The optical resolution of FS5 UHD camera unit is close to $1 \mu \mathrm{m}$, which means that the smallest particles are not visible in practice and thus not included in the calculations. Length of the fibers decreased from around $0.8 \mathrm{~mm}$ (T0/U0) to $40 \mu \mathrm{m}$ (T3/ $\mathrm{U} 3)$, when grinding time increased and finally led to a suspension containing mainly CNF (i.e., U3 and T3). Also fiber width decreased from around $19 \mu \mathrm{m}$ (T0/ U0) to around $2 \mu \mathrm{m}$ (T3/U3). The proportion of fines (i.e., particles which length and width are smaller than $200 \mu \mathrm{m})$ were mainly in the two smallest size categories (i.e., $0-40 \mu \mathrm{m}$ and $40-80 \mu \mathrm{m}$ ) with U3 and T3 samples while in primary board pulp (T0/U0) there is only around 5\% fines. Based on the fiber analysis, the fiber properties of the DES-pretreated samples and the samples without chemical treatment (reference samples) were similar.

The surface structure of the board handsheets $\left(160 \mathrm{~g} / \mathrm{m}^{2}\right)$ was visualized directly from the surface of the prepared sheets with the absence (Fig. 1a) and the presence of additional reinforcement CNF (T1, T2 and T3, Fig. 1b-d). CNF were observed on the surface of the handsheets, and smaller fibrils were visible on the surface of the sheets when the fibrillation level increased (i.e., T3 vs. T1/T2).

\section{Energy consumption of the CNF production} and the strength properties of the nanopapers

Table 3 presents the grinding energy demand for the production of the CNF reinforcements. The grinding time varied from 0 to $114 \mathrm{~min}$, while the corresponding energy consumption was $0-8.8 \mathrm{kWh} / \mathrm{kg}$ of product. The consumed energy used in this research was well in line what have been noticed earlier in many publications related to mechanical fine friction grinding (Eriksen et al. 2008; Klemm et al. 2011; Laitinen et al. 2017; Ämmälä et al. 2019). The reinforcement potential of CNF was evaluated from the nanopapers fabricated directly from CNF without board fibers (Table 3). Overall, the strength properties of the CNF obtained from the DES-treated samples were better in comparison to the CNF produced using mechanical grinding without chemical pretreatment, and the strength increased as a function of grinding time. For example, the tensile strength of the nanopapers from the DES-treated CNF increased from 14.0 to 181.75 MPa (T0 and T3), while the maximum tensile strength of the reference CNF was 154.17 MPa (U3). These values are comparable to many of the recently published strength values of lignocellulosic nanopapers and films (Spence et al. 2010; Rojo et al. 2015; Visanko et al. 2017; Hietala et al. 2018).

Mechanical properties of the board handsheets

The CNF produced from recycled boxboard were used as a reinforcement in the board handsheets. During the 

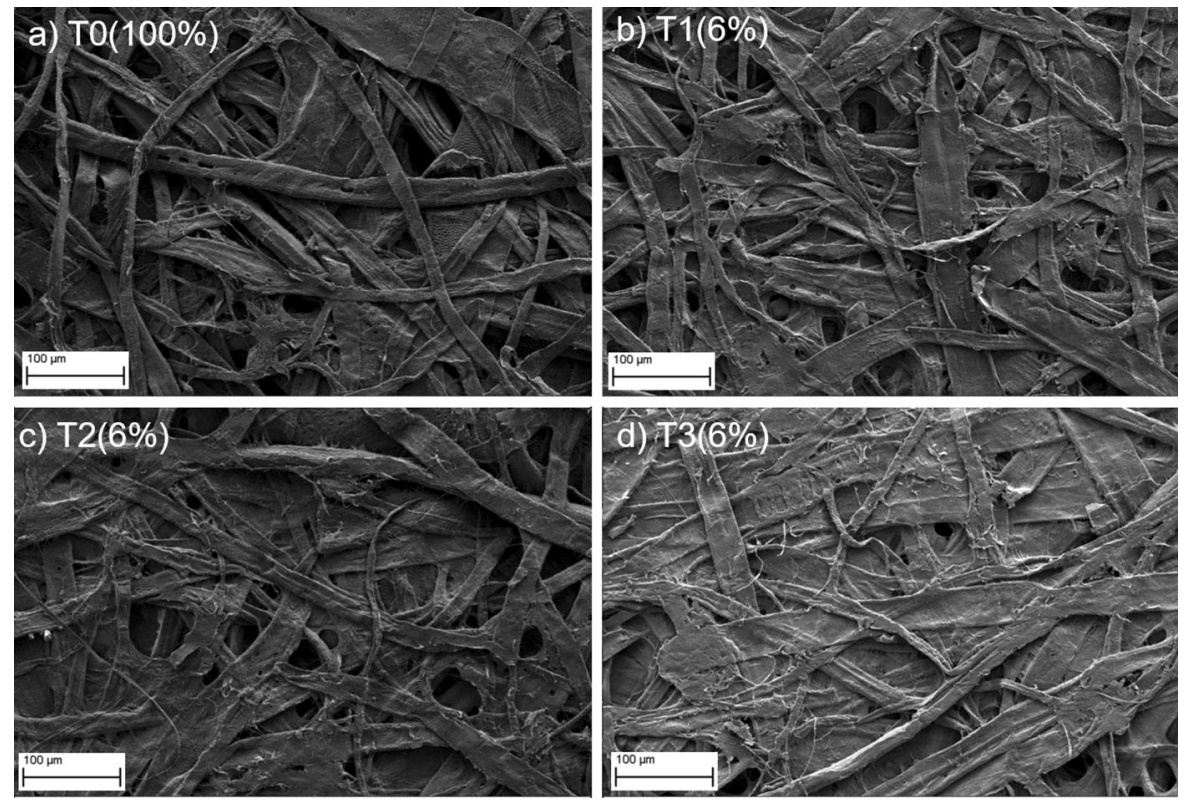

Fig. 1 Surface structure of the board handsheets with the absence and presence of CNF as reinforcements; a board from 100\% of T0; b board containing $6 \mathrm{wt} \%$ of T1; c board containing $6 \mathrm{wt} \%$ of T2; d board containing 6 wt $\%$ of T3

preparation of the handsheets, the drainage time was observed to increase almost linearly (Fig. 2) as a function of the reinforced CNF dosage, which varied from 2 to $6 \mathrm{wt} \%$. Moreover, the increase in the grinding time of the fibers decreased the water removal, i.e., it increased the drainage time (U1 $\rightarrow$ $\mathrm{U} 2 \rightarrow \mathrm{U} 3)$. A similar trend was observed for the DEStreated and reference CNF. However, the total retention of the board handsheets were very high (from approx. 97.5-99.5\%), which was in practice $97.5 \%$

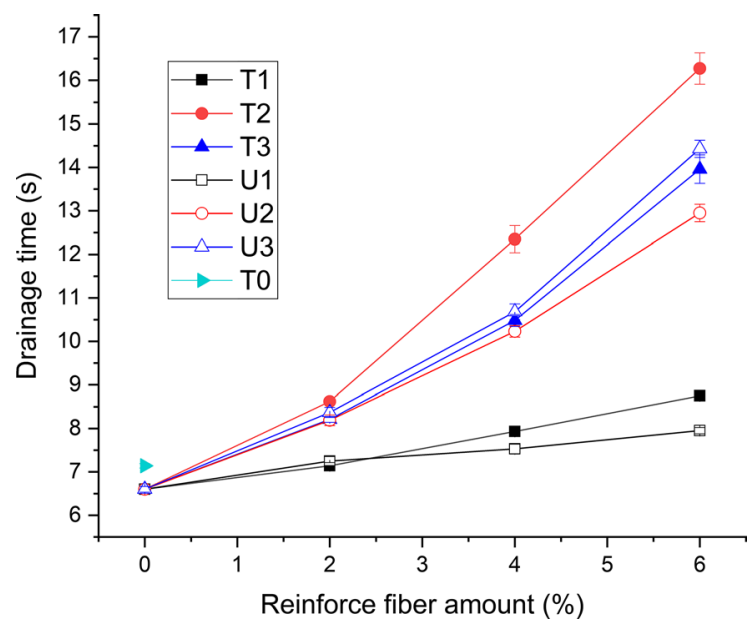

Fig. 2 Drainage time of the board handsheets with the highest dosage of reinforcement $\mathrm{CNF}$ (6 wt\%) and with CNF of the smallest size (U3 and T3). This indicates that the retention of the reinforcement CNF was also high without the use of any retention chemicals (around 70\%).

The reinforcement of the mechanical properties of the board sheets by the addition of CNF is most likely connected to the enhanced bonding between the board fibers promoted by the CNF (da Costa Correia et al. 2016). Therefore, CNF can increase the density and stiffness of a sheet, and decrease the sheet bulk. In the present study, the highest density (Fig. 3) and lowest bulk (Fig. S3) were observed, as expected, in the board sheets with the highest amount $(6 \mathrm{wt} \%)$ of the most fibrillated reinforcement CNF (U3). For example, the sheet density increased from 577 to $684 \mathrm{~kg} / \mathrm{m}^{3}$, while bulk decreased from 1.73 to $1.46 \mathrm{~cm}^{3} / \mathrm{g}$ with $\mathrm{U} 3$. Density trends and therefore in turns bulk trends seems to be similar in both for the DES-treated and reference CNF.

The tear index and strain of the board handsheets are presented as a function of the CNF reinforcement (Fig. 4.) Both the tear index and strain increased with larger CNF dosages, except for the sheet containing U1. However, the effect of CNF on the tear strength was either relatively small or it plateaued at low dosages. Furthermore, the improvement in strain 


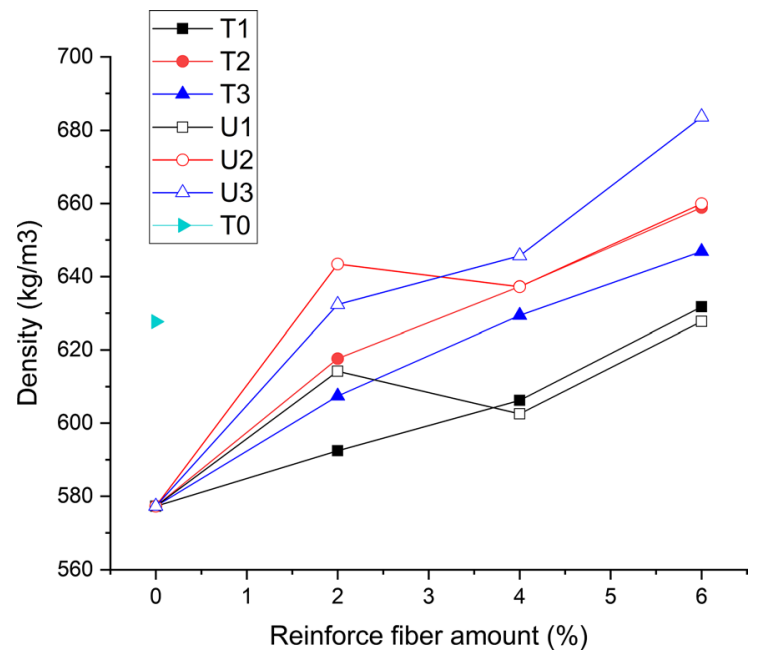

Fig. 3 Densities of the prepared board handsheets

induced by CNF was very small ( $<1 \%$ unit). Generally, the DES-treated CNF sample resulted in better values than the reference CNF.

To evaluate the costs attributed to using $\mathrm{CNF}$ as reinforcements in the board handsheet, some preliminary calculations were conducted. The estimated price of the electricity was $0.13 € / \mathrm{kWh}$; the price of recycled boxboard was $0.08 € / \mathrm{kg}$. Technical grade of urea costs around $200 € / \mathrm{t}$ and choline chloride around $350 € / \mathrm{t}$ (Laitinen et al. 2017). We used in these calculations recycling rate of 10 times and efficiency of chemical recycling $97 \%$ and the used consistency of pulp solution during DES-treatment was 5\%. Based on

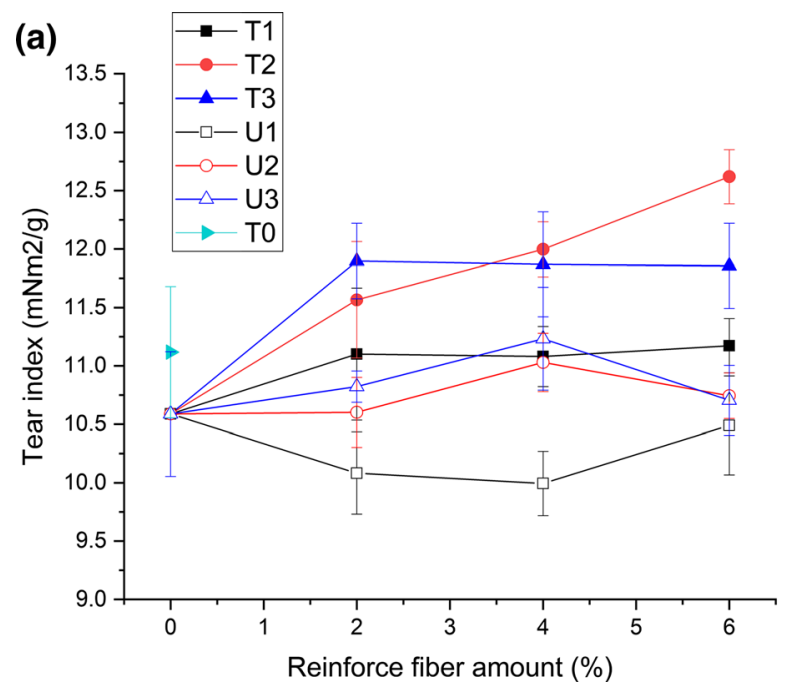

calculations chemical pretreatment with used DESsystem increased the raw material cost from 0.08 to $0.107 € / \mathrm{kg}$, which is around $34 \%$. We noticed also that both the grinding level of CNF and their loading in the board sheet have a significant impact on the final price of the board. For example, increasing the T3 dosage from 2 to $6 \mathrm{wt} \%$ increased the final product price of the board by approximately $160-212 \%$. Overall, the costs associated with using DES-treated CNF were around $30 \%$ higher when compared to reference $\mathrm{CNF}$ (Figs. S4-S6) recycled board. Because the energy consumption, chemical costs and costs associated with CNF use increased notably when the CNF grinding level increased, the most important mechanical properties of the board were compared to the energy consumption and relative manufacturing price of the strengthened recycled board to analyze the optimal use of $\mathrm{CNF}$ as a reinforcement.

The tensile strength of the handsheets increased almost linearly as a function of the CNF dosage (Fig. 5). CNF treated with DES enhanced the tensile strength to a greater extent than the addition of reference CNF (Fig. 5), and the highest strength value was obtained with $\mathrm{T} 3$. The best tensile strength index was $61 \%$ higher (i.e., T3 [6\%]) than that of the reference board handsheet $(34.0 \mathrm{kNm} / \mathrm{kg})$. Moreover, it was observed that pulp from the DES-pretreatment had better strength properties in comparison to the untreated pulp. However, by considering the total chemical costs associated with the pulp slurry

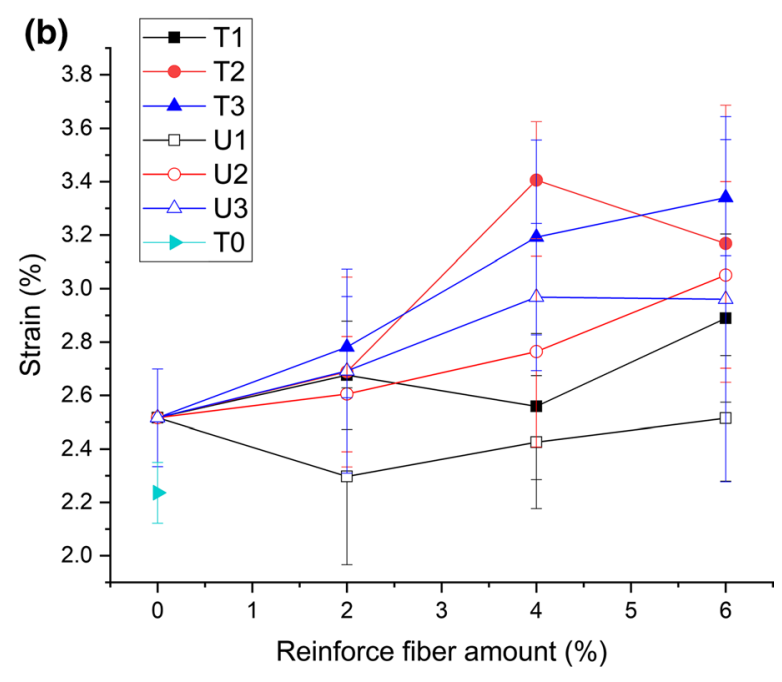

Fig. 4 Tear index (a) and strain values (b) of prepared board handsheets 


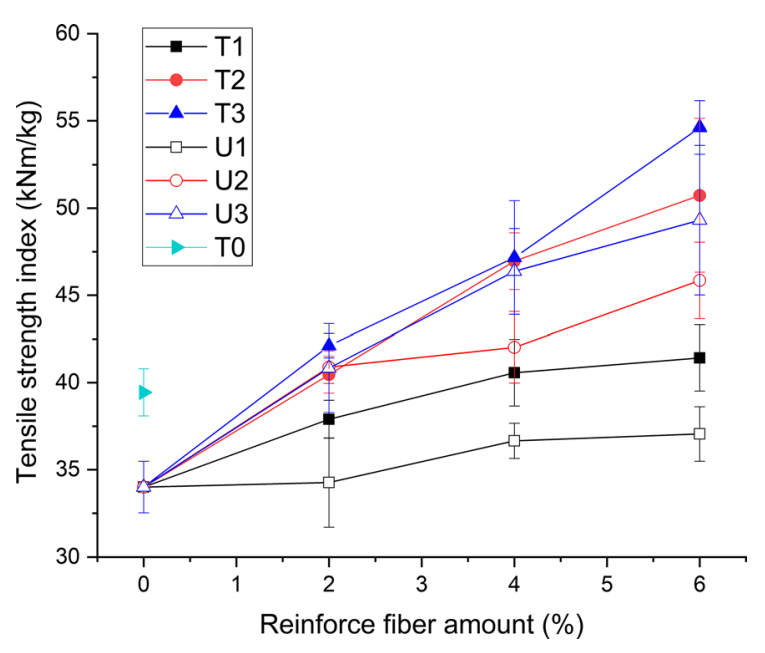

Fig. 5 Tensile strength index against reinforcement fiber amount of the prepared board handsheets

pretreatment, a more economical way to enhance the strength properties would be to add untreated mechanical grinded CNF as the reinforcement. Of the CNF used, the samples obtained from moderate grinding (U2) resulted in the most cost-efficient board sheets (Fig. S4). The obvious reason for this phenomenon is that the energy consumption of grinding increased significantly at the end of the grinding process (i.e., $\mathrm{U} 2 \rightarrow \mathrm{U} 3$ ), while the improvement in strength properties was not as pronounced.

The trend for the tensile stiffness index of the board sheets was similar to the trend for the tensile strength index (Fig. 6). A nearly linear increase in the tensile

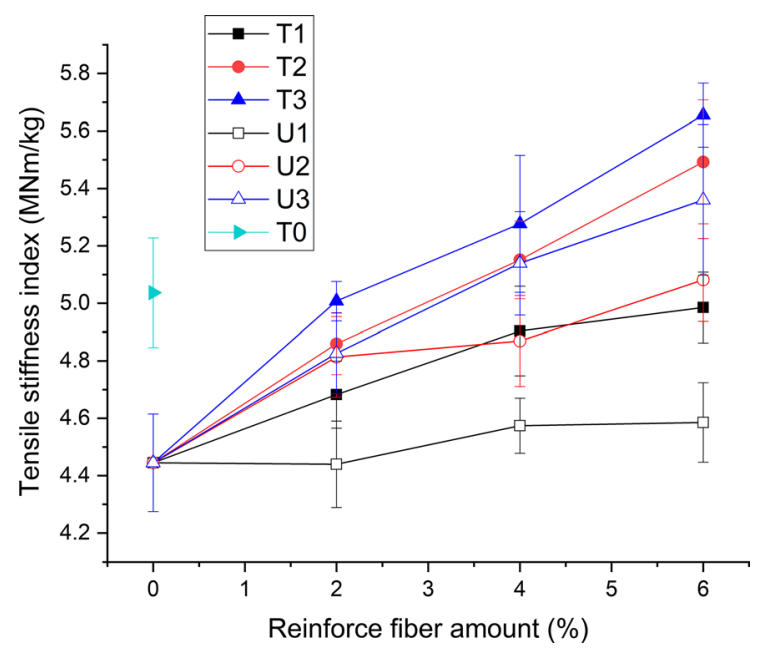

Fig. 6 Comparison of the tensile stiffness index based on the amount of reinforcement fiber of the prepared board handsheets stiffness index was observed, and a maximum increase of $27 \%$ was noted with the CNF treated with DES and the highest grinding level (T3). Furthermore, the most economical way to increase the tensile stiffness was to add the $\mathrm{CNF}$ with a moderate grinding level (i.e., U2, Fig. S5). For example, the $6 \mathrm{wt} \%$ dosage of $\mathrm{T} 2$ resulted in a tensile stiffness index of approximately $5.5 \mathrm{MNm} / \mathrm{kg}$ with a relative cost of $160 \%$, while cost related to the use of the $6 \mathrm{wt} \%$ of U3 was approximately $190 \%$ with the stiffness index of approximately $5.3 \mathrm{MNm} / \mathrm{kg}$.

In the best case, the tensile stress (z-direction tensile strength) was $85 \%$ higher (i.e., T3 [6\%]) than that of the reference board handsheet (i.e., without grinding) (Fig. 7). However, the differences between the DES-treated CNF and the reference CNF were small. Similar to the tensile strength and stiffness values, the most cost-efficient use of reinforcement was to add the CNF with the moderate grinding levels (i.e., U2) to enhance the z-direction tensile strength (Fig. S6).

Overall, the results clearly demonstrate that the best way to improve the mechanical properties of the board sheet was to add approximately $4 \mathrm{wt} \%$ of untreated mechanical grinded CNF from the moderate grinding levels (those that used grinding energy $3-4 \mathrm{kWh} / \mathrm{kg}$ ) as a reinforcement material. Doing so only increased the relative price of the manufactured board by 15-20\%, but the tensile strength index improved $25-40 \%$, the tensile stiffness index was $10-20 \%$, and the z-direction tensile strength was $40-60 \%$ (Fig. S4-

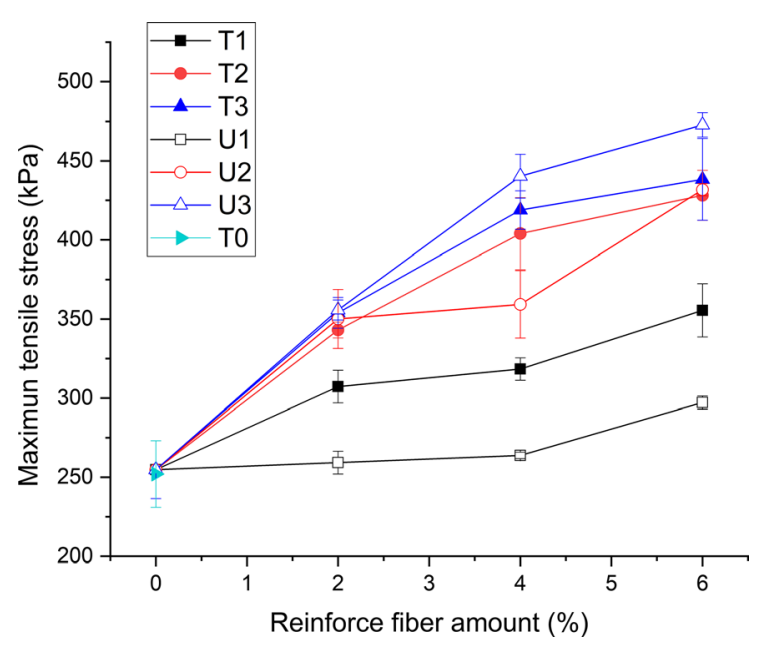

Fig. 7 The tensile stress (z-direction tensile strength) reinforcement fiber amount of the prepared board handsheets 
Table 4 Comparison of the improved strength properties of paper products published in recently

\begin{tabular}{|c|c|c|c|c|c|c|}
\hline Publication & Reinforced fiber & $\begin{array}{l}\text { Added } \\
\text { amount } \\
(\%)\end{array}$ & $\begin{array}{l}\text { Retention } \\
\text { agent/filler }\end{array}$ & $\begin{array}{l}\text { Increase } \\
\text { of tensile } \\
\text { strength } \\
(\%)\end{array}$ & $\begin{array}{l}\text { Increase of } \\
\text { z-direction } \\
\text { tensile } \\
\text { strength }(\%)\end{array}$ & Final product \\
\hline Eriksen et al. (2008) & Kraft pulp CMF & $1-8$ & No/no & $7-21$ & Not analyzed & TMP \\
\hline Hii et al. (2012) & SW kraft pulp CMF & $2.5-5$ & Yes/yes & $3-13$ & $20-35$ & Newsprint grade TMP \\
\hline $\begin{array}{l}\text { Djafari Petroudy et al. } \\
\text { (2014) }\end{array}$ & $\begin{array}{l}\text { Mechanical and enzymatic } \\
\text { treated CMF }\end{array}$ & $1-5$ & Yes/no & $22-40$ & Not analyzed & Bagasse pulp \\
\hline Hellström et al. (2014) & $\begin{array}{l}\text { Fenton and enzymatic treated } \\
\text { CNF }\end{array}$ & 5 & Yes/yes & $5-35$ & $2-50$ & СТMP \\
\hline Su et al. (2014) & HW kraft pulp CMF & 10 & Yes/no & $270-300$ & Not analyzed & HW kraft pulp \\
\hline $\begin{array}{l}\text { Delgado-Aguilar et al. } \\
\text { (2015a) }\end{array}$ & Tempo-oxidized CNF & $1.5-4.5$ & Yes/yes & $40-82$ & $32-56$ & Deinked pulp \\
\hline Hassan et al. (2015) & $\begin{array}{l}\text { Enzymatic and TEMPO- } \\
\text { oxidized CNF }\end{array}$ & $2.5-20$ & No/no & $14-62$ & Not analyzed & $\begin{array}{l}\text { Softwood and bagasse } \\
\text { pulps }\end{array}$ \\
\hline $\begin{array}{l}\text { Delgado-Aguilar et al. } \\
\text { (2015b) }\end{array}$ & HW kraft pulp CNF & 3 & Yes/no & $70-200$ & Not analyzed & HW kraft pulp \\
\hline $\begin{array}{l}\text { Brodin and Eriksen } \\
(2015)\end{array}$ & $\begin{array}{l}\text { Carboxymethylated and } \\
\text { fractionated TMP }\end{array}$ & $0-20$ & No/no & $1-15$ & Not analyzed & TMP \\
\hline Mashkour et al. (2015) & Acetylated CNF & $0-10$ & Yes/no & $0-17$ & Not analyzed & SW kraft pulp \\
\hline Hietala et al. (2016) & Dicarboxyl acid cellulose CNF & $0.25-4$ & Yes/yes & $0-21$ & Not analyzed & Fluting board \\
\hline $\begin{array}{l}\text { Suopajärvi et al. } \\
\text { (2017) }\end{array}$ & $\begin{array}{l}\text { Kraft pulp, Fluting and Board } \\
\text { CNF }\end{array}$ & 4 & Yes/yes & $12-34$ & Not analyzed & $\begin{array}{l}\text { Kraft pulp, Fluting } \\
\text { and Board }\end{array}$ \\
\hline Tajik et al. (2018) & Bagasse pulp CNF & $0.1-2$ & Yes/no & $15-49$ & Not analyzed & Bagasse pulp \\
\hline Bossu et al. (2019) & SW kraft pulp CMF & $1-10$ & No/no & $3-48$ & $1-95$ & SW kraft pulp \\
\hline This study & Boxboard CNF & $2-6$ & No/no & $1-45$ & $2-85$ & Recycled boxboard \\
\hline This study & DES-treated boxboard CNF & $2-6$ & No/no & $11-60$ & $20-72$ & Recycled boxboard \\
\hline
\end{tabular}

S6). Obviously, the board strength properties can still be improved by adding CNF with a higher grinding level $(>4 \mathrm{kWh} / \mathrm{kg})$ or by increasing the amount of reinforced $\mathrm{CNF}(>4 \mathrm{wt} \%$ ), but this is not meaningful from an economic point of view. Furthermore, higher dosages of $\mathrm{CNF}$ from higher grinding levels would increase the drainage time and cause problems in the actual board manufacturing process. Moreover, it must be highlighted that the total chemical costs needed for the DES-pretreatment and the recycling of chemicals (i.e., urea and choline chloride) increased relative much (around 30\%) of the final product price when DES-treatment is used in the CNF preparation. In summary, the results suggest that the grammage of prepared board could be decreased by adding CNF as the reinforcement material, and the treated product would still achieve similar strength properties as the original board without any reinforced fibers.
In the Table 4 have been compared improved strength properties of different paper products published in recent years. As can be noticed different nanocellulose reinforced fibers have typically a positive impact on the strength properties of various paper products, but some of research's were used very expensive chemicals and very energy intensive grinding method like high pressure homogenization instead of mechanical grinding. Additionally, most of studies focused on paper strengthening and only a few scientific studies have focused on the effects of CNF on paperboard properties.

\section{Conclusions}

This study's findings showed that, by selecting suitable grinding levels and dosages of CNF, it is 
possible to notably enhance the strength of the board sheet. Moreover, a balance between the board processing parameters (retention, drainage time) and the board mechanical properties can be achieved by tailoring the amount of CNF that is added. The strength properties of the manufactured board sheets improved several dozen percentages when CNF obtained from recycled boxboard was used as a reinforcement. It was also observed that the strength properties of the pulp from the DES-pretreatment were better than those of the untreated pulp. However when taking account chemical pretreatment with used DESsystem the raw material cost increased around 34\% and therefore the most economical way to improve the tensile strength properties of boards is to add untreated mechanical grinded CNF with around a $4 \%$ moderate grinding level (using a grinding energy level around $3-4 \mathrm{kWh} / \mathrm{kg}$ ) directly to the board pulp slurry as the reinforcement material.

Acknowledgments Open access funding provided by University of Oulu including Oulu University Hospital. The authors would like to acknowledge the funding provided by the Council of Oulu Region, granted by the European Regional Development Fund of the European Union for the New bioproducts and-chemicals from cellulose side streams using DES-based refining concept project (SelDES).

\section{Compliance with ethical standards}

Conflict of interest The authors declare that they have no conflict of interest.

Open Access This article is licensed under a Creative Commons Attribution 4.0 International License, which permits use, sharing, adaptation, distribution and reproduction in any medium or format, as long as you give appropriate credit to the original author(s) and the source, provide a link to the Creative Commons licence, and indicate if changes were made. The images or other third party material in this article are included in the article's Creative Commons licence, unless indicated otherwise in a credit line to the material. If material is not included in the article's Creative Commons licence and your intended use is not permitted by statutory regulation or exceeds the permitted use, you will need to obtain permission directly from the copyright holder. To view a copy of this licence, visit http://creativecommons.org/licenses/by/4.0/.

\section{References}

Ämmälä A, Laitinen O, Sirviö JA, Liimatainen H (2019) Key role of mild sulfonation of pine sawdust in the production of lignin containing microfibrillated cellulose by ultrafine wet grinding. Ind Crops Prod 140:111664. https://doi.org/ 10.1016/j.indcrop.2019.111664

Bossu J, Eckhart R, Czibula C et al (2019) Fine cellulosic materials produced from chemical pulp: the combined effect of morphology and rate of addition on paper properties. Nanomaterials 9:321. https://doi.org/10.3390/ nano9030321

Brodin FW, Eriksen $\varnothing$ (2015) Preparation of individualised lignocellulose microfibrils based on thermomechanical pulp and their effect on paper properties. Nord Pulp Pap Res J 30:443-451. https://doi.org/10.3183/npprj-2015-3003-p443-451

da Costa Correia V, dos Santos V, Sain M et al (2016) Grinding process for the production of nanofibrillated cellulose based on unbleached and bleached bamboo organosolv pulp. Cellulose 23:2971-2987. https://doi.org/10.1007/ s10570-016-0996-9

Delgado-Aguilar M, González I, Pèlach MA et al (2015a) Improvement of deinked old newspaper/old magazine pulp suspensions by means of nanofibrillated cellulose addition. Cellulose 22:789-802. https://doi.org/10.1007/s10570014-0473-2

Delgado-Aguilar M, González Tovar I, Tarrés Q et al (2015b) Approaching a low-cost production of cellulose nanofibers for papermaking applications. BioResources. https://doi. org/10.15376/biores.10.3.5345-5355

Djafari Petroudy SR, Syverud K, Chinga-Carrasco G et al (2014) Effects of bagasse microfibrillated cellulose and cationic polyacrylamide on key properties of bagasse paper. Carbohydr Polym 99:311-318. https://doi.org/10. 1016/j.carbpol.2013.07.073

Eriksen $\varnothing$, Syverud K, Gregersen $\varnothing$ (2008) The use of microfibrillated cellulose produced from kraft pulp as strength enhancer in TMP paper. Nord Pulp Pap Res J 23:299-304

González I, Vilaseca F, Alcalá M et al (2013) Effect of the combination of biobeating and NFC on the physico-mechanical properties of paper. Cellulose 20:1425-1435. https://doi.org/10.1007/s10570-013-9927-1

Hassan EA, Hassan ML, Oksman K (2011) Improving bagasse pulp paper sheet properties with microfibrillated cellulose isolated from xylanase-treated bagasse. Wood Fiber Sci 43:76-82

Hassan ML, Bras J, Mauret E et al (2015) Palm rachis microfibrillated cellulose and oxidized-microfibrillated cellulose for improving paper sheets properties of unbeaten softwood and bagasse pulps. Ind Crops Prod 64:9-15. https://doi.org/10.1016/j.indcrop.2014.11.004

Hellström P, Hejnesson-Hulten A, Paulson M et al (2014) Fenton pre-treated microfibrillated cellulose evaluated as a strength enhancer in the middle ply of paperboard. Nord Pulp Pap Res J 29:732-740

Hietala M, Ämmälä A, Silvennoinen J, Liimatainen H (2016) Fluting medium strengthened by periodate-chlorite oxidized nanofibrillated celluloses. Cellulose 23:427-437. https://doi.org/10.1007/s10570-015-0801-1

Hietala M, Varrio K, Berglund L et al (2018) Potential of municipal solid waste paper as raw material for production of cellulose nanofibres. Waste Manag 80:319-326. https:// doi.org/10.1016/j.wasman.2018.09.033 
Hii C, Gregersen $\varnothing W$, Chinga-Carrasco G, Eriksen $\varnothing$ (2012) The effect of MFC on the pressability and paper properties of TMP and GCC based sheets. Nord Pulp Pap Res J 27:388

Kamel S (2007) Nanotechnology and its applications in lignocellulosic composites, a mini review. Express Polym Lett 1:546-575. https://doi.org/10.3144/expresspolymlett. 2007.78

Kangas H, Lahtinen P, Sneck A et al (2014) Characterization of fibrillated celluloses. A short review and evaluation of characteristics with a combination of methods. Nord Pulp Pap Res J 29:129-143

Katz S, Beatson RP, Scallan AM (1984) The determination of strong and weak acidic groups in sulfite pulps. Sven Papperstidning 87:R48-R53

Klemm D, Kramer F, Moritz S et al (2011) Nanocelluloses: a new family of nature-based materials. Angew Chem Int Ed 50:5438-5466. https://doi.org/10.1002/anie.201001273

Laitinen O, Suopajärvi T, Österberg M, Liimatainen H (2017) Hydrophobic, superabsorbing aerogels from choline chloride-based deep eutectic solvent pretreated and silylated cellulose nanofibrils for selective oil removal. ACS Appl Mater Interfaces 9:25029-25037. https://doi.org/10.1021/ acsami.7b06304

Lavoine N, Desloges I, Dufresne A, Bras J (2012) Microfibrillated cellulose-its barrier properties and applications in cellulosic materials: a review. Carbohydr Polym 90:735764. https://doi.org/10.1016/j.carbpol.2012.05.026

Li P, Sirviö JA, Haapala A, Liimatainen H (2017) Cellulose nanofibrils from nonderivatizing urea-based deep eutectic solvent pretreatments. ACS Appl Mater Interfaces 9:2846-2855. https://doi.org/10.1021/acsami.6b13625

Li P, Sirviö JA, Asante B, Liimatainen H (2018) Recyclable deep eutectic solvent for the production of cationic nanocelluloses. Carbohydr Polym 199:219-227. https:// doi.org/10.1016/j.carbpol.2018.07.024

Mashkour M, Afra E, Resalati H, Mashkour M (2015) Moderate surface acetylation of nanofibrillated cellulose for the improvement of paper strength and barrier properties. RSC Adv 5:60179-60187. https://doi.org/10.1039/C5RA081 $61 \mathrm{~K}$

Missoum K, Martoïa F, Belgacem MN, Bras J (2013) Effect of chemically modified nanofibrillated cellulose addition on the properties of fiber-based materials. Ind Crops Prod 48:98-105. https://doi.org/10.1016/j.indcrop.2013.04.013

Nourbakhsh A, Ashori A (2010) Particleboard made from waste paper treated with maleic anhydride. Waste Manag Res 28:51-55. https://doi.org/10.1177/0734242X09336463

Ojala J, Visanko M, Laitinen O et al (2018) Emulsion stabilization with functionalized cellulose nanoparticles fabricated using deep eutectic solvents. Molecules 23:2765. https://doi.org/10.3390/molecules23112765

Rattaz A, Mishra SP, Chabot B, Daneault C (2011) Cellulose nanofibres by sonocatalysed-TEMPO-oxidation. Cellulose 18:585-593. https://doi.org/10.1007/s10570-011-9529-8

Rojo E, Peresin MS, Sampson WW et al (2015) Comprehensive elucidation of the effect of residual lignin on the physical, barrier, mechanical and surface properties of nanocellulose films. Green Chem 17:1853-1866. https://doi.org/10.1039/ C4GC02398F

Sehaqui H, Zhou Q, Berglund LA (2013) Nanofibrillated cellulose for enhancement of strength in high-density paper structures. Nord Pulp Pap Res J 28:182-189

Selkälä T, Sirviö JA, Lorite GS, Liimatainen H (2016) Anionically stabilized cellulose nanofibrils through succinylation pretreatment in urea-lithium chloride deep eutectic solvent. Chemsuschem. https://doi.org/10.1002/cssc.201600903

Singh BS, Lobo HR, Shankarling GS (2012) Choline chloride based eutectic solvents: magical catalytic system for carbon-carbon bond formation in the rapid synthesis of $\beta$ hydroxy functionalized derivatives. Catal Commun 24:70-74. https://doi.org/10.1016/j.catcom.2012.03.021

Siró I, Plackett D (2010) Microfibrillated cellulose and new nanocomposite materials: a review. Cellulose 17:459-494. https://doi.org/10.1007/s10570-010-9405-y

Sirviö JA (2018) Cationization of lignocellulosic fibers with betaine in deep eutectic solvent: facile route to charge stabilized cellulose and wood nanofibers. Carbohydr Polym 198:34-40. https://doi.org/10.1016/j.carbpol.2018. 06.051

Sirviö JA, Visanko M, Liimatainen H (2015) Deep eutectic solvent system based on choline chloride-urea as a pretreatment for nanofibrillation of wood cellulose. Green Chem 17:3401-3406. https://doi.org/10.1039/C5GC0039 $8 \mathrm{~A}$

Spence KL, Venditti RA, Rojas OJ et al (2010) The effect of chemical composition on microfibrillar cellulose films from wood pulps: water interactions and physical properties for packaging applications. Cellulose 17:835-848. https://doi.org/10.1007/s10570-010-9424-8

Su J, Zhang L, Batchelor W, Garnier G (2014) Paper engineered with cellulosic additives: effect of length scale. Cellulose 21:2901-2911. https://doi.org/10.1007/s10570-014-0298-z

Suopajärvi T, Sirviö JA, Liimatainen H (2017) Nanofibrillation of deep eutectic solvent-treated paper and board cellulose pulps. Carbohydr Polym 169:167-175. https://doi.org/10. 1016/j.carbpol.2017.04.009

Tajik M, Torshizi HJ, Resalati H, Hamzeh Y (2018) Effects of cationic starch in the presence of cellulose nanofibrils on structural, optical and strength properties of paper from soda bagasse pulp. Carbohydr Polym 194:1-8. https://doi. org/10.1016/j.carbpol.2018.04.026

Visanko M, Sirviö JA, Piltonen P et al (2017) Mechanical fabrication of high-strength and redispersible wood nanofibers from unbleached groundwood pulp. Cellulose 24:4173-4187. https://doi.org/10.1007/s10570-017-1406-7

Publisher's Note Springer Nature remains neutral with regard to jurisdictional claims in published maps and institutional affiliations. 